\title{
Plasma cell dyscrasia behavior in a referral hospital in southern Colombia: younger, clinically and paraclinically worse than reported
}

\author{
Luis Carlos Alvarez-Perdomo ${ }^{1,2,4}$, LM Leiva Panqueva ${ }^{3,4}$, AF Mosquera-Chavarro ${ }^{1,4}$, Carlos Perez-Castañeda ${ }^{5}$, \\ Kenny Buitrago-Toro ${ }^{1,4}$, Silvana Jimenez-Salazar ${ }^{1,4}$
}

${ }^{1}$ Department of Internal Medicine, University Hospital Hernando Moncaleano Perdomo. ${ }^{2}$ Semiology professor, Faculty of Health Sciences, Universidad Surcolombiana, Neiva, Colombia. ${ }^{3}$ Medical epidemiologist, Emergency service, University Hospital Hernando Moncaleano Perdomo, Neiva, Colombia. ${ }^{4}$ MI Dneuropsy research Group, Universidad Surcolombiana, Neiva, Colombia. ${ }^{5}$ Medical doctor, North Side Hospital, Atlanta, Georgia, United States, zip code 30005.

\begin{abstract}
Objectives: Plasma cell dyscrasias are diseases characterized by clonal proliferation and accumulation of cells producing monoclonal immunoglobulins. These diseases have not been studied in our region and we don't know if their behavior is similar to that reported in the literature. That's why we evaluated multiple characteristics in southern Colombia.

Methods: analytical cross-sectional study of patients with confirmed diagnosis of a plasma cell dyscrasias were included.

Results: 60 patients included in our study, 65\% were men, with an average age of 58.8 years (CI 96\% 55.8 - 61.93). Bone pain was the most frequent symptom (88\%). The most frequent dyscrasia was multiple myeloma and in these patients we found a high percentage of hemoglobin less than $10 \mathrm{mg} / \mathrm{dl}$, creatinine greater than $2 \mathrm{mg} / \mathrm{dl}$ and serum calcium higher than $11 \mathrm{mg} / \mathrm{dl}(77 \%, 38 \%$ and $37 \%$, respectively). Half of the patients had a time course of symptoms greater than 4 months and $43 \%$ had plasma cells in bone marrow greater than $60 \%$. 65\% of patients had elevated levels of serum B2-microglobulin (>5.5 mg/L) and in-hospital mortality was $15 \%$. We found a statistically significant association between mortality and gender (PR 6.5) and between mortality and hemoglobin ( $p=0.039$ ).

Conclusion: Patients with plasma cell dyscrasia in southern Colombia are younger, consult late, in an advanced stage of their disease, with greater renal damage, hypercalcemia and anemia than reported in the literature, also a high tumor burden due to high plasma cell infiltration into bone marrow and high values of serum B2-microglobulin.
\end{abstract}

Key words: Plasma cell dyscrasia, monoclonal gammopathy, multiple myeloma, tumor load, Colombia.

\section{INTRODUCTION}

Plasma cell dyscrasias constitute a broad spectrum of diseases characterized by clonal proliferation and accumulation of cells producing monoclonal heavy and light chain restricted immunoglobulins (known as paraprotein or M proteins) ${ }^{1}$. These disorders include monoclonal gammopathy of uncertain significance, multiple myeloma (MM) and its variants (asymptomatic multiple myeloma, symptomatic multiple myeloma, plasma cell leukemia, nonsecretory myeloma), plasmacytoma and its variants; osteosclerotic myeloma (POEMS syndrome), immunoglobulin deposition diseases and Waldenstrom macroglobulinemia. In the literature, they are within the spectrum of the same disease, but most reports and studies focus on the Multiple myeloma. Our study tried to collect the whole plasma cell dyscrasia spectrum, nevertheless the symptomatic spectrum of the disease corresponds to multiple myeloma and our data are directed to this particular pathology, due to the low prevalence of the other entities found in our study and their low expression of symptoms ${ }^{2,3}$. MM is a malignant neoplasm of plasma cells that accumulate in bone marrow, leading to bone destruction and marrow failure. It's the most important plasma cell dyscrasia, accounting for approximately $10 \%$ of all hematological malignancies ${ }^{4}$. Higher incidence is reported in developed countries, probably owing to the availability of better diagnostic techniques. Also the incidence is higher in black individuals (11.9 per 100.000) and lower in Asian and Hispanic and more prevalent in men than in women ${ }^{5,6,7}$. The diagnosis is based on the presence of a monoclonal protein, bone manifestations and infiltration of plasma cells in the bone marrow. These entities are relatively rare and their prognosis is poor, with less of 2 year survival on the worst scenarios ${ }^{8}$.

On the other hand, although associations with strong evidence to reveal clear clinical risk factors in this group of patients have not been elucidated, some frequently encountered conditions have been documented such as advanced age, male gender, african-american race and family history of these diseases ${ }^{9,10,11}$. Despite those clinical risk factors that could lead to a better treatment response the most powerfull prognostic factor is related to genetic abnormalities, principally del(17p) and del(1p32) $)^{12}$.

Treatment of this hematological malignancy has evolve from corticosteroids and melphalan to high dose chemotherapy associated with autologous stem-cell transplantation and recently immunomodulatory drugs like thalidomide, lenalidomide, proteasome inhibitors and biologic therapies with better outcomes ${ }^{13,14}$.

In Latin America, most publications are limited to case reports with manifestations or atypical characteristics of some of these diseases. The few investigations on clinical behavior have been carried out only in patients with multiple myeloma, such is the case of studies carried out in Chile, Cuba, Argentina, Peru, Mexico and Brazil ${ }^{15}$, where patients with multiple myeloma have been characterized, reporting statistical data similar to those of the rest of the world, with average age of presentation above 60 years ${ }^{16}$. 
No studies have been carried out covering all this group of pathologies in Colombia, and it is unknown if the behavior of this spectrum of diseases in this population is similar at the rest of the world, for which the characterization of this condition was postulated.

\section{MATERIALS AND METHODS}

Cross-sectional study, where the demographic, clinical and paraclinical characteristics of patients with plasma cell dyscrasias of the University Hospital of Neiva in a period between January 2005 and December 2016 were studied. Data from the pathology unit and patients whose histological diagnosis met the inclusion criteria were selected. In parallel, patients registered with any of the ICD-10 codes related to the included pathologies were reviewed. Subsequently, and once the patients who entered the study were identified, a search was made on clinical records of the oncology unit, in order to complement and corroborate the information obtained. We included adult patients assessed at the university hospital of Neiva, a tertiary referral hospital in southern Colombia, with a histopathological diagnosis related to some plasma cell dyscrasia available in the database of the pathology unit of this institution during the study period and their respective medical records. Additionally patients with a diagnosis of ICD-10 (International Classification of Diseases, tenth version) related to plasma cell diseases were included.

A convenience sampling was carried out including the total population considering the low prevalence of these disorders.

The sociodemographic data and clinical variables were obtained from the medical records. The review of medical records was carried out by four medical doctors from the University Hospital of Neiva. The data was entered by two independent operators, with subsequent reconciliation of the data by the main researcher, in order to detect erroneous values and missing information.

After the data collection, organization, tabulation and coding variables in the statistical program IBM SPSS 20, a descriptive and inferential statistical analysis was completed and generated information of percentages, averages, proportions of the compared data and measures of association between the different variables.

Univariate descriptive analysis were initially completed. For qualitative variables, frequency measurements were calculated; and for the quantitative variables, measures of central tendency, dispersion and position were determined. Normal tests of Kolmogorov-Smirnov and Shapiro-Wilk were performed on all quantitative variables, according to the sample value. Subsequently, a bivariate analysis was performed using different statistical tests according to the type of distribution of the variables, such as Pearson and Spearman correlations between two quantitative variables, the chi-square test between qualitative variables, and $\mathrm{t}$-student and $\mathrm{U}$ tests of Mann Whitney between quantitative and qualitative variables.

\section{RESULTS}

A total of 95 patients were obtained; 23 medical records were not available in physical or digital file. Nine patients did not correspond to a diagnosis of plasma cell dyscrasia and information was incomplete in three cases, which is why they were not included in the analysis of the information.

The minimum age was 35 years and a maximum of 86 years, with a mean of 58.8 years (IC 55.90-61.9) (Figure 1). 65\% of the patients were male, mainly from urban areas $(32 \%$ vs. $28 \%$ ). In relation to race, it was found the vast majority of patients were mestizos (95\%) and only one patient was African-American. Family history of cancer was found only in $6.8 \%$, with none relation for any type of neoplasia.

Figure 1. Percentage accumulated according to the age of the patients with diagnosis of plasma cell dyscrasia.

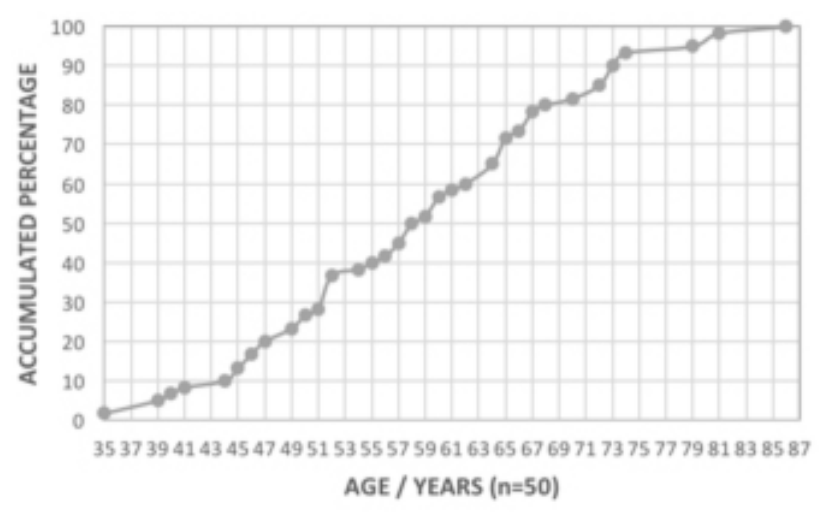

Multiple myeloma was the most frequent plasma cell dyscrasia, with $80 \%$ (two cases of POEMS syndrome were found (3.3\%), two cases of non-secretory multiple myeloma (3.3\%). Solitary plasmacytoma was second place in $13.3 \%$; a patient with extramedullary plasmacytoma (1.7\%) and an individual with heavy chain disease, also called Franklin's disease $(1.7 \%)$. After all, 50 patients had multiple myeloma or one of its varieties. No patients were found with Waldenstrom's macroglobulinemia, plasma cell leukemia, light chain deposit disease or primary amyloidosis (Table 1).

Table 1. Distribution according to the type of dyscrasia of patients with diagnosis of plasma cell dyscrasias, $n=60$.

\begin{tabular}{|l|c|c|}
\hline Type of plasma cell dyscrasia & Frequency & Percentage (\%) \\
\hline Enf. heavy chains (franklin) & 1 & 1,7 \\
\hline Multiple myeloma & 45 & 75 \\
\hline Multiple myeloma biclonal & 1 & 1,7 \\
\hline Multiple myeloma not secretor & 2 & 3,3 \\
\hline Plasmocytoma & 8 & 13,3 \\
\hline Extramedullary plasmocytoma & 1 & 1,7 \\
\hline POEMS Syndrome & 2 & 3,3 \\
\hline Total & 60 & 100 \\
\hline
\end{tabular}


The clinical manifestations were found in patients with multiple myeloma; bone pain was the most common symptom with an $85 \%$. A little more than a half of the patients also reported weight loss at the time of presentation (57\%). Neurological symptoms were a less frequent finding, present in $36.7 \%$ of patients. Bone alterations occurred in $88 \%$ of patients, with osteolytic lesions predominating (35\%), followed by pathological fractures (28.3\%). (Figures 2 and 3 )

Figure 2. Distribution according to the clinical signs of patients diagnosed with multiple myeloma, $n=50$.

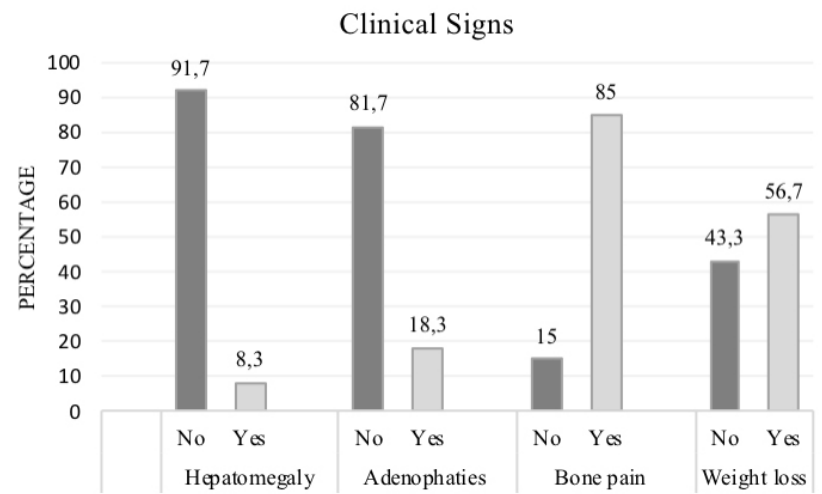

The average time of evolution of the symptoms was 4.5 months until admission, and 20 days for the time from admission to diagnosis. The most common Lab report found was anemia, followed by elevated creatinine and hypercalcemia. $77 \%$ of the patients had a hemoglobin value of $10 \mathrm{mg} / \mathrm{dl}$ or below. Creatinine greater than $2 \mathrm{mg} / \mathrm{dl}$ in $38 \%$ of patients and the presence of hypercalcemia (serum calcium greater than $11 \mathrm{mg} / \mathrm{dl}$ ) was recorded in 37\% of cases (Table 2).

Figure 3. Distribution according to the type of bone alteration of patients with a diagnosis of plasma cell dyscrasia, $n=50$.

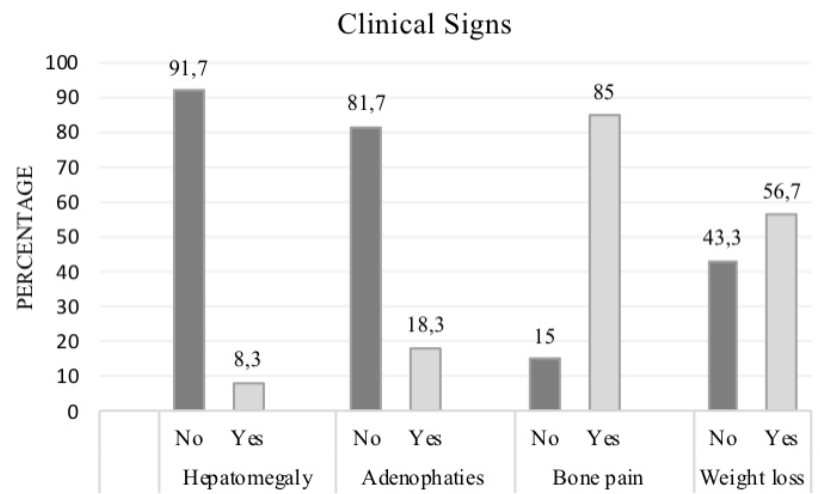

Table 2. Laboratory results in 50 patients with multiple myeloma and its subtypes.

\begin{tabular}{|l|c|c|c|c|c|}
\hline & No. of patiens & Result & Rank & Distribution & $\%$ of patiens \\
\hline Hemoglobin $(\mathrm{gr} / \mathrm{dl})$ & 50 & Mean: 8.8 & $4.8-14.0$ & $<10$ & 77 \\
\hline Creatinine $(\mathrm{mg} / \mathrm{dl})$ & 50 & Median: 1.26 & $0.45-10.6$ & $>2.0$ & 38 \\
\hline Calcium $(\mathrm{mg} / \mathrm{dl})$ & 50 & Median: 10.4 & $7.2-16.2$ & $>11.0$ & 37 \\
\hline
\end{tabular}

In regard of plasma cell percentage, this value was found in 30 of the 50 patients with multiple myeloma or its subtypes (Figure 4). The median was $45 \%$ and $43 \%$ of the patients had a value greater than or equal to $60 \%$ of plasma cells in bone marrow. The B2-microglobulin in this same sample $(n=50)$ showed a median of $6.0 \mathrm{mg} / \mathrm{L}$ and $65 \%$ of the patients were above $5.5 \mathrm{mg} / \mathrm{L}$.

32 patients had a record of protein electrophoresis, 24 patients had production of $\mathrm{M}$ protein, of which $\lg \mathrm{G}$ was the most frequent $(50 \%)$, followed by IgA (18\%). In $18 \%$, only

Figure 4. Distribution of patients with plasma cell dyscrasias for the following variables: percentage of plasma cells in bone marrow, M protein, light chain and serum B2-microglobulin value.

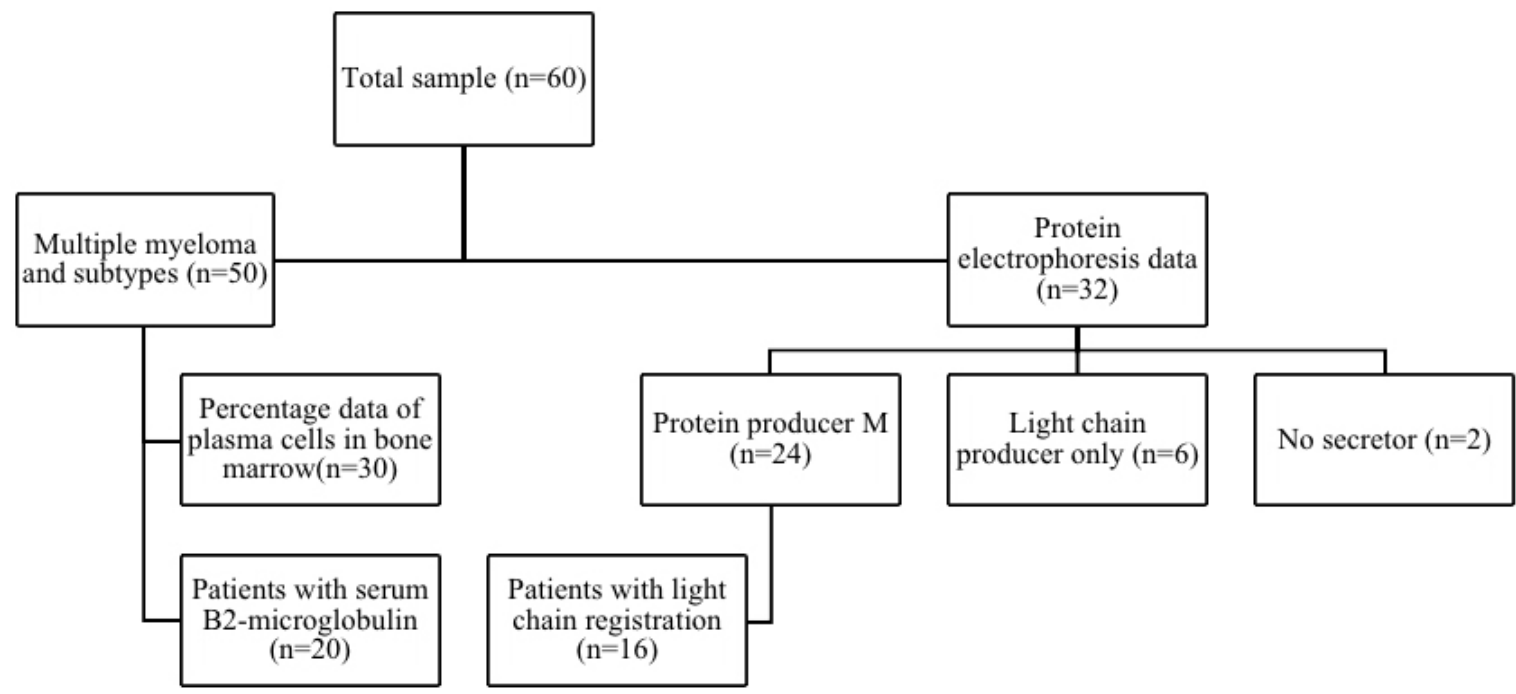


light chain production was also found, being Kappa chain the most frequent (50\% Vs $43.7 \%$ ). One case was treated as biclonal multiple myeloma where Kappa and Lambda chains were identified (Figure 5).

Figure 5. Distribution of $M$ protein in patients with multiple myeloma, $n=32$.

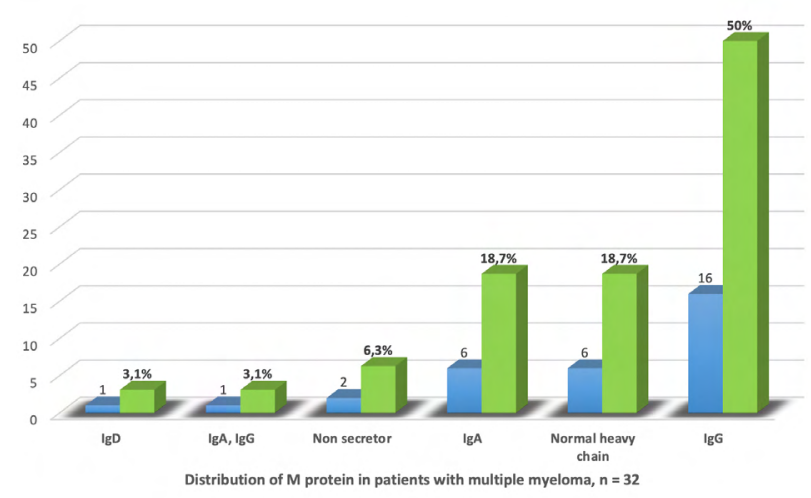

In-hospital mortality was recorded in $15 \%$, and $18 \%$ in the case of multiple myeloma. When comparing mortality with qualitative variables, a statistically significant association between gender and in-hospital mortality was found using the chi-square test, with a $p=0.04$ and a prevalence ratio (PR) value of 6.5, with an interval of confidence (Cl) 95\% (1.48 28.53) for multiple myeloma.

The association between the variables of mortality and hemoglobin performed with t-student test showed that there is a statistically significant difference in the mean hemoglobin between patients who died and did not die $(p=0.039)$, being lower in the group that died. The patients who died had a mean hemoglobin of $7.7 \mathrm{gr} / \mathrm{dl}$ in contrasts with the average of those who survived $(9.5 \mathrm{gr} / \mathrm{dl})$ ). (Table 3 )

Significant differences were found between the medians of the patients who died and did not die in the case of the percentage of plasma cells in the bone marrow ( $80 \%$ Vs $40 \%$, respectively), as well as for the serum B2-microglobulin (12.9\%). Vs. 6 mg/L)

\section{DISCUSSION}

In this study, an average of 58 years of age was found, which is not consistent with reports in the western literature, where an average of approximately 70 years is described on regards of patients with multiple myeloma ${ }^{17}$. It has been shown that only $10 \%$ and $2 \%$ of patients are under 50 and 40 years old, respectively ${ }^{18}$.

Age averages similar to the present research have also been reported, such as in the Egyptian published in 2014, where the average age was 58.5 years ${ }^{19}$ and in a Colombian study conducted in the Santa Fe Foundation of Bogota in patients with multiple myeloma finding an average of 58 years, $26 \%$ of them were under 50 years old 20 .

By gender, the highest prevalence was in men (65\%), slightly above the male: female ratio described in the literature (1.8:
1 vs 1.4: 1). This gender distinction is probably important in terms of mortality. The literature reports a higher incidence in black and African-American individuals (approximately 2 to 3 times compared to the white race) $)^{21}$, which did not correlate with the results, nor was it found that the prevalence of cancer in first-degree relatives was more frequent than the general population.

For patients with multiple myeloma in our study bone pain was the predominant symptom, occurring in $88 \%$ of patients, higher than reported in the literature where it is described in approximately $58 \%$ of cases. Weight loss was a frequent complaint, found in $57 \%$ of our population, more than double what was reported in a registry of 1027 patients diagnosed with multiple myeloma in the Mayo Clinic $^{17,21,22}$.

Neurological symptoms are not uncommon in patients with plasma cell dyscrasias, and are the most frequent presentation symptoms in multiple myeloma, after CRAB symptoms (Calcium, Renal failure, Anemia, Bone disease) ${ }^{23}$. Peripheral neuropathy is common and is frequently associated with plasma cell dyscrasias, which may correspond to $10 \%$ of patients with idiopathic peripheral neuropathy and as high as $20 \%$ in patients with multiple myeloma. In this study, a high neurological compromise was found, with paresis of the lower limbs more frequent ${ }^{24,25}$.

Bone lesions visualized on a conventional radiograph, which may include osteolytic lesions or the presence of fractures, are described in $80 \%$ of patients at the time of diagnosis. A record similar to that found in this study (74\%), where injuries also predominated osteolytic ${ }^{26}$.

An average duration of 56 days has been described, from the time of onset of symptoms to the medical consultation for multiple myeloma, representing the longest duration among 10,953 patients with 28 different types of cancer, as reported in a study published in the British Journal of Cancer in 2015. This does not resemble the present results, where $50 \%$ of the patients had a medical consultation greater than or equal to 4 months. Situation that may be a reflection of failures in access to health services and lack of education in the general population to consult quickly before the progression of these symptoms, which induce a late diagnosis and poor prognosis ${ }^{27}$.

From the point of view of laboratory reports; hemoglobin, serum creatinine and serum calcium values were taken into account, as they are fundamental markers of organic damage and an indispensable condition in the definitive diagnosis of the majority of patients with multiple myeloma ${ }^{28}$. In this way, it was possible to demonstrate that anemia does correspond to the most frequent findings, although the large series only describes it in $35 \%$ of patients. Creatinine and serum calcium are also reported lower (19 and 13\%, respectively) ${ }^{17}$, indicating that our patients presented with greater anemia, kidney damage and hypercalcemia.

The compromise at the spinal level found is similar to reported in the literature, however, it is noteworthy that a large part of 
the patients (43\%) had an infiltration in the medulla of more than $60 \%$, indicating a large tumor load. Findings in protein electrophoresis were consistent previously described, and for the case of B2 microglobulin it was found that the vast majority of patients had high values, indicating an advanced stage in the evolution of the disease. The high levels of serum B2-microglobulin have been associated with a higher tumor load and it has also been related to renal failure, which in turn leads to an unfavorable prognosis ${ }^{28,29}$.

In-hospital mortality was high in our patients, and even more so in those with multiple myeloma. This compared with the study that analyzed 3,107 patients with multiple myeloma evaluated in a medical research center in the United Kingdom, where an early mortality (first 60 days of diagnosis) of $10 \%$ was found ${ }^{30}$.

A bivariate analysis was performed in which a statistically significant association was found between gender and inhospital mortality with a value of $p=0.04$ and a prevalence ratio $(\mathrm{PR})$ of 6.5 , posing the hypothesis that women can have a greater chance of dying. Additionally, it was found that the hemoglobin levels were different between those who died and those who did not die, this in a statistically significant way with a value of $p=0.039$, in such a way that it is possible to hypothesize that having a low hemoglobin, around of $7 \mathrm{gr} /$ $\mathrm{dl}$, significantly increases the chance of death. Large studies such as the one mentioned in the Mayo Clinic have identified some risk factors for adverse prognosis, among which the most significant are the patient's functional status, albumin concentration and age. Hemoglobin less than $10 \mathrm{gr} / \mathrm{dl}$ is described, but with a low relative risk $(\mathrm{RR}=1.3)$ and gender has not been reported as a favoring or adverse factor ${ }^{17}$.

\section{CONCLUSIONS}

The clinical findings and the predominant symptoms are similar to those reported in the literature, as well as the findings in protein electrophoresis. However, in our patients these disorders were diagnosed in younger people and often in advanced stages of their evolution. The proportion of patients with renal damage and hypercalcemia was high and a strong tumor load was shown due to the high levels of serum B2-microglobulin and the high percentage of plasma cell infiltration within the bone marrow in patients with multiple myeloma.

The time of evolution since the beginning of symptoms was prolonged, much longer than described for this type of disease, with a negative impact in the clinical course of the disease.
The main limitations on our research are all those associated with biases of the cross-sectional studies (selection, biases due to prevalent cases, information, cause-effect relationship not always verifiable), and incomplete information in protein electrophoresis reports. However, its main strength was including the spectrum of plasma dyscrasias, in addition to providing an approach to these pathologies of low incidence and prevalence and allow us to raise some possible hypotheses and in a later prospective study perform stratified analyzes, controlling variables of confusion to establish association and risk measures.

Although the nature of our study does not allow the identification of causal relationships, a statistically significant association was found between mortality and female gender, as it was found with low levels of hemoglobin, which raises the initial hypothesis of higher mortality in females and hemoglobin around $7 \mathrm{gr} / \mathrm{dl}$ that must to be confirmed in further investigations.

\section{Clinical practice points}

- Plasma cell dyscrasias constitute a broad spectrum of diseases characterized by accumulation of immunoglobulins, known as paraprotein or $\mathrm{M}$ proteins, within which multiple myeloma is the most prevalent.

- Despite western literature reports multiple myeloma patients were over 60 years old Latin American, and especially in Colombians, clinicians should raise disease suspicion also in younger ones with CRAB symptoms.

- Awareness of risk factors as time of evolution since the beginning of symptoms, female gender, anemia, grade of renal failure and hypercalcemia must be taken in count to a worst prognosis in low income institutions were molecular technology it's not available.

- More research must be done with a bigger sample, including different institutions and cities all over the country to determine specific behavior of plasma cell dyscrasias in Colombia and Latin America.

\section{DISCLOSURE}

The authors have stated that they have no conflicts of interest or economic financing. 


\section{REFERENCES}

1. Soh KT, Tario JD, Wallace PK. Diagnosis of Plasma Cell Dyscrasias and Monitoring of Minimal Residual Disease by Multiparametric Flow Cytometry. Clinics in laboratory medicine. 2017;37(4):821-53.

2. Ghobrial IM, Laubach JP, Richardson PG. Plasma cell dyscrasias. ASH-SAP: American Society of Hematology Self-Assessment Program: American Society of Hematology. 2010:581-604.

3. International Myeloma Working G. Criteria for the classification of monoclonal gammopathies, multiple myeloma and related disorders: a report of the International Myeloma Working Group. British journal of haematology. 2003;121(5):749-57.

4. Curado MP, Oliveira MM, Silva DRM, Souza DLB. Epidemiology of multiple myeloma in 17 Latin American countries: an update. Cancer Medicine.7(5):2101-8.

5. Kumar SK, Rajkumar V, Kyle RA, van Duin M, Sonneveld P, Mateos M-V, et al. Multiple myeloma. Nature Reviews Disease Primers. 2017;3:17046.

6. Kirtane K, Lee SJ. Racial and ethnic disparities in hematologic malignancies. Blood. 2017; 130(15):1699-705.

7. Turesson I, Bjorkholm M, Blimark CH, Kristinsson S, Velez R, Landgren O. Rapidly changing myeloma epidemiology in the general population: increased incidence, older patients, and longer survival. European journal of haematology. 2018.

8. Wallin A, Larsson SC. Body mass index and risk of multiple myeloma: A meta-analysis of prospective studies. European Journal of Cancer. 2011;47(11):1606-15.

9. Turesson I, Velez R, Kristinsson SY, Landgren O. Patterns of Multiple Myeloma During the Past 5 Decades: Stable Incidence Rates for All Age Groups in the Population but Rapidly Changing Age Distribution in the Clinic. Mayo Clinic Proceedings. 2010;85(3):225-30.

10. Kyle RA, Therneau TM, Rajkumar SV, Offord JR, Larson DR, Plevak MF, et al. A Long-Term Study of Prognosis in Monoclonal Gammopathy of Undetermined Significance. New England Journal of Medicine. 2002;346(8):564-9.

11. Kyle RA, Remstein ED, Therneau TM, Dispenzieri A, Kurtin PJ, Hodnefield JM, et al. Clinical Course and Prognosis of Smoldering (Asymptomatic) Multiple Myeloma. New England Journal of Medicine. 2007;356(25):2582-90.

12. Perrot A, Corre J, Avet-Loiseau H. Risk Stratification and Targets in Multiple Myeloma: From Genomics to the Bedside. American Society of Clinical Oncology Educational Book. 2018;38:675-80.

13. Mahajan S, Tandon N, Kumar S. The evolution of stem-cell transplantation in multiple myeloma. Therapeutic advances in hematology. 2018;9(5):123-33.

14. Zheleznyak A, Shokeen M, Achilefu S. Nanotherapeutics for multiple myeloma. Wiley Interdisciplinary Reviews: Nanomedicine and Nanobiotechnology. 2018:e1526.

15. Conté GL, Figueroa GM, Lois WV Cabrera MC, León AR, García HL, et al. [Clinical features and survival of Chilean patients with multiple myeloma]. Rev Med Chil. 2007;135(9):1111-7.
16. Hungria VT, Maiolino A, Martinez G, Duarte GO, Bittencourt R, Peters L, et al. Observational study of multiple myeloma in Latin America. Annals of hematology. 2017;96(1):65-72.

17. Kyle RA, Gertz MA, Witzig TE, Lust JA, Lacy MQ, Dispenzieri A, et al. Review of 1027 Patients With Newly Diagnosed Multiple Myeloma. Mayo Clinic Proceedings. 2003;78(1):21-33.

18. Devine H, Verina D. Young Adults with Multiple Myeloma. Seminars in Oncology Nursing. 2017;33(3):316-31.

19. Kassem NM, El Zawam H, Kassem HA, El Nahas T, El Husseiny NM, El Azeeim HA. A descriptive study of plasma cell dyscrasias in Egyptian population. Journal of the Egyptian National Cancer Institute. 2014;26(2):67-71.

20. Segovia J, Duarte M, Restrepo JG, Saavedra CE, Andrade RE. Mieloma múltiple en el Hospital Universitario Fundación Santa Fe de Bogotá (1983-2006). Acta Médica Colombiana. 2008;33(4).

21. Waxman AJ, Mink PJ, Devesa SS, Anderson WF, Weiss BM, Kristinsson SY, et al. Racial disparities in incidence and outcome in multiple myeloma: a populationbased study. Blood. 2010;116(25):5501-6.

22. Becker N. Epidemiology of multiple myeloma. Multiple Myeloma: Springer; 2011. p. 25-35.

23. Couriel DR, Ricker H, Steinbach M, Lee CJ. Neurologic Manifestations of Blood Dyscrasias. Hematology/Oncology Clinics. 2016;30(4):723-31.

24. Dispenzieri A, Kyle RA. Multiple myeloma: clinical features and indications for therapy. Best Practice \& Research Clinical Haematology. 2005;18(4):553-68.

25. Bayat E, Kelly JJ. Neurological complications in plasma cell dyscrasias. Handb Clin Neurol. 2012;105:731-46.

26. Kaushik R, Thakur RK, Gulati A, Sharma Sk. Multiple Myeloma: Clinico-hematological profile in a tertiary care hospital: a three years study. 1. 2017;4(5):A470-5.

27. Lyratzopoulos G, Saunders CL, Abel GA, McPhail S, Neal RD, Wardle J, et al. The relative length of the patient and the primary care interval in patients with $28 \mathrm{com}$ mon and rarer cancers. British Journal of Cancer. 2015;112(s1):S35-S40.

28. Alexander DD, Mink PJ, Adami HO, Cole P, Mandel JS, Oken MM, et al. Multiple myeloma: a review of the epidemiologic literature. International journal of cancer. 2007;120(S12):40-61.

29. Greipp PR, San Miguel J, Durie BGM, Crowley JJ, Barlogie B, Bladé J, et al. International staging system for multiple myeloma. J Clin Oncol. 2005;23(15):3412-20.

30. Augustson BM, Begum G, Dunn JA, Barth NJ, Davies F, Morgan G, et al. Early Mortality After Diagnosis of Multiple Myeloma: Analysis of Patients Entered Onto the United Kingdom Medical Research Council Trials Between 1980 and 2002-Medical Research Council Adult Leukaemia Working Party. JCO. 2005;23(36):9219-26. 